duction. . . . A neat inversion, this, of the more usual idea that evolutionary biology is the gradualist science and geological history the Uniformitarian one. Indeed ${ }^{13} \mathrm{C}$ studies on ancient sediments, reviewed by Shidlowski et al., fit perfectly well with the notion that a biosphere of similar scale to today was already present 3.5 , possibly 3.8 Gyr ago: there is a typical biological (autotrophic) signature in the isotope ratios of reduced and oxidized materials, although it must be said that such signatures can be forged by non-biological processes.

Chapters by Schopf, Malcolm R. Walter and Hans J. Hoffmann on Precambrian fossils serve to underline the stability of many biological forms. Not all that much seems to have been happening between 3.5 Gyr ago and towards the end of the Precambrian $(0.57 \mathrm{Gyr}$ ago) when truly multicellular forms of life came on the scene. The 3.5 Gyr date is of rocks from Western Australia that contain fossil stromatolites (microbial colonies) as well as fossils of filamentous bacteria similar to modern members of stromatolite communities. To be told that of 43 cases of pre-2.5-Gyr-old sets of "microfossil-like objects" there are only two that are well proven, is a little worrying - one wonders whether more work might cast doubt here too. Well, there is no absolute security in this field and the evidence seems pretty good to me. If it holds it is the nearest we have yet got to the origin of life (although still not very near if these are fossils of anything at all like modern prokaryotes).

Past sequences of events within the biosphere can perhaps be inferred from the ways in which present biochemical subsystems depend on each other. Howard Gest and Schopf see sugars as primary materials, with fermentation and then (non-oxygenic) photosynthesis having been achieved early on (by $3.5 \mathrm{Gyr}$ ago on the basis of isotope and fossil evidence). J.M. Hayes makes a case for oxygenproducing photosynthesis having appeared by about $2.8 \mathrm{Gyr}$ ago: a wide spread of carbon isotope ratios in reduced materials of that sort of age fits with the idea that around then both oxygen-rich and oxygenpoor sedimentary basins were common. Whatever the exact timing, the more general oxygenation of the environment is seen by David J. Chapman and Schopf to have left its mark in the structures of modern biochemical pathways which indicate a progression from our remoter ancestors, which could not put up with oxygen, through forms that could tolerate it, to those that needed oxygen to survive.

This is a good-looking book with plenty of data and models attractively presented in pictures, diagrams and tables. I can see it in studies, in laboratories and even on coffee tables. It should help to generate some new addicts for an untidy, unsafe but exciting field.

A.G. Cairns-Smith is Reader in Chemistry at the University of Glasgow.

\section{Astronomical city}

\section{David W. Hughes}

The Story of Astronomy in Edinburgh.

By Hermann A. Brück.

Edinburgh University Press: 1983.

$$
\text { Pp.151. £8.50. }
$$

EDINBURGH is the home of a famous university and a Royal Observatory, and the history of astronomy in that city is a tale of the intricate symbiotic relationship between the two establishments. Both are old. Nineteen-eighty-three saw the 400th anniversary of the University and 1972 the 150th anniversary of the Royal Observatory, so it is a fitting time to delve into the development of astronomy in the city. Between the years of 1957 and 1975 Hermann A. Brück held "by far the most attractive astronomical post in the United Kingdom", that of being jointly Astronomer Royal for Scotland and Regius Professor of Astronomy at the University of Edinburgh. He has written a delightful book which will appeal to a wide variety of readers.

The story divides easily into three parts, the first centring around Calton Hill for which William Playfair designed an observatory modelled on the Greek Temple of the Winds. This replaced the Old Observatory on the same hill, which had been used by the Astronomical Institution of Edinburgh, a society founded in 1811 , and the first British society whose activities were entirely devoted to the pursuit of astronomy. Their aim was to establish an observatory which could be used both for scientific research and for popular observation. In 1785 Robert Blair was appointed as the first professor of astronomy and this was followed in 1822 by King George IV being "graciously pleased to permit the Observatory on Calton Hill to be styled The Royal Observatory". In 1834 the Astronomical Institution transferred the use of the Observatory to the University on the condition that the Government of the day appointed an Observer who would be titled Astronomer Royal for Scotland and

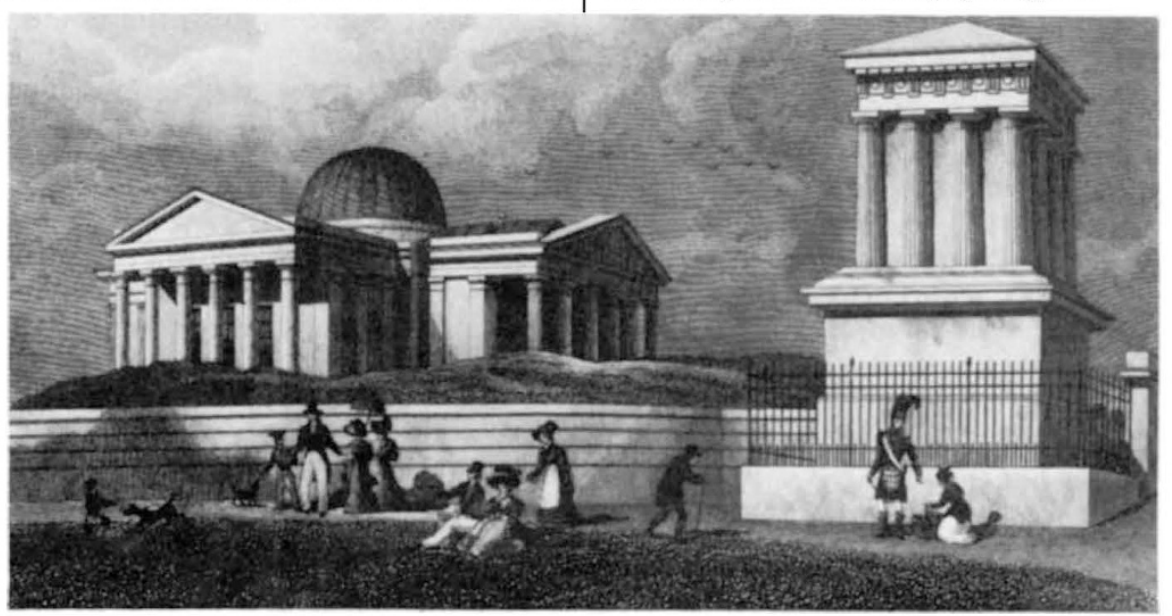

Calton Hill in the 1820s, adorned by the New Observatory and Playfair's Monument. would also occupy the Chair of Astronomy at the University of Edinburgh. Thomas Henderson was appointed and was followed by Charles Piazzi Smyth who dominated Edinburgh astronomy between 1846 and 1888 . personalities in the scientific world during the Victorian era. He founded "mountain astronomy", realizing that height improved the effectiveness and precision of astronomical observations, immersed himself in pyramidology and ignored his university duties as there were "generally no students at all for so untoward, despised and poverty-stricken a subject in Scotland"'.

Things obviously had to change and Ralph Copeland, Smyth's successor, witnessed the building of a new observatory at Blackford Hill to the south of Edinburgh and the transfer to that observatory of the Dunecht instruments which previously belonged to the 26th Earl of Crawford. Spectroscopic astrophysics flourished and under the successive leadership of Frank Dyson, Ralph Sampson and W.M.H. Greaves the observatory developed spectrophotometry and highprecision photographic photometry.

In 1957 Hermann Brück took over and in his 18 years supervised a great expansion of the observatory, the numbers of staff growing from less than ten on his arrival to well over a hundred on his retirement. Research in Edinburgh led to the development of autoguider systems, photoelectric exposure control for spectroscopes, ultraviolet observatories in space, satellite tracking and the GALAXY and COSMOS machines which can automatically scan photographic plates and measure the positions and brightness of stars and galaxies.

Brück writes that his "years on Blackford Hill have been extremely happy ones", a happiness which echoes through his story. There can be few better advertisements for astronomy, or for Edinburgh as a place to pursue the subject.

David $W$. Hughes is a Lecturer in Physics and Astronomy at the University of Sheffield.
Smyth was one of the most fascinating 